\title{
Renovascular and renoprotective properties of telmisartan: clinical utility
}

This article was published in the following Dove Press journal: International Journal of Nephrology and Renovascular Disease 12 March 2010

Number of times this article has been viewed

\author{
Marco Ladino \\ Ivonne Hernandez Schulman \\ Nephrology-Hypertension Section, \\ Veterans Affairs Medical Center \\ and Division of Nephrology and \\ Hypertension and Interdisciplinary \\ Stem Cell Institute, University of \\ Miami Miller School of Medicine, \\ Miami, FL, USA
}

\begin{abstract}
Chronic kidney disease (CKD) affects approximately 26 million adults in the United States and millions of others are at increased risk. Type 2 diabetes and hypertension are the two main causes of CKD. Blood pressure control is critical to slow the progression of CKD. Despite adequate control, however, patients continue to progress to end-stage renal disease. Angiotensin receptor blockers (ARBs) are commonly used in the management of hypertension and CKD and have been shown to exert renoprotective effects that are in addition to, but independent of, blood pressure lowering. Telmisartan is a long-acting ARB with pharmacological properties beyond blockade of the angiotensin II type 1 receptor, including activation of the peroxisome proliferator activated receptor- $\gamma$ (PPAR- $\gamma)$. This article reviews the beneficial renal and vascular protective effects of telmisartan.
\end{abstract}

Keywords: kidney diseases, hypertension, vascular diseases, angiotensin II receptor, PPAR- $\gamma$

\section{Introduction}

The incidence and prevalence of essential hypertension continues to rise worldwide. Changes in diet, daily physical activity, environment, and lifestyle have made hypertension a more common and difficult to control disease. Of greatest concern are the diseases that arise as a consequence of undetected and/or uncontrolled hypertension, including cerebro-vascular, coronary artery, peripheral vascular, and chronic kidney diseases (CKD).

Many classes of medications are currently used to treat hypertension, such as diuretics, beta-blockers, calcium channel blockers, renin inhibitors, angiotensin converting enzyme (ACE) inhibitors, and angiotensin receptor blockers (ARBs). Among the ARBs there is one medication that has special pharmacological properties in addition to blocking the angiotensin II type 1 receptor; this medication is telmisartan. It has been shown to lower blood pressure as well as exert cardiovascular and renoprotective effects independently of blood pressure reduction.

In the present review we will discuss the pharmacology and the beneficial properties of telmisartan in the management of hypertension.

\section{Pharmacology}

Angiotensin II is the most studied effector peptide of the renin-angiotensin system. It is produced from angiotensin I by ACE and has effects in multiple organs of the human body. There are 4 types of angiotensin receptors (AT1, AT2, AT3, AT4). AT1 is the receptor that enables most of the hemodynamic changes in the body that are 
related to angiotensin II, these include vasoconstriction and stimulation of aldosterone release (Figure 1). In response to angiotensin II, there is an increase in glomerular pressure and glomerular permselectivity as well as activation of fibrosis and cellular growth in the kidney.

Telmisartan is a non-peptide angiotensin II type 1 receptor (AT1) antagonist with high lipophilicity and the longest half-life compared with other ARBs. ${ }^{1,2}$ Available in oral preparation, it is highly bound to plasma proteins ( $>99.5 \%)$, mainly albumin. It is metabolized by conjugation, is not metabolized by the cytochrome P450 system, and is eliminated in feces. It has a greater affinity for the AT1 receptor than angiotensin II (>3000 fold).

Like ACE inhibitors and other ARBs, telmisartan should be avoided in pregnant and nursing patients. The side effects are similar to those of other ARBs, including hyperkalemia, hypotension, and creatinine elevation due to decrease of the glomerular filtration rate. These parameters should be monitor closely after the medication is started. It has minimal drug interactions, namely digoxin and lithium levels may increase and these should be monitored regularly. After administration of telmisartan, levels of angiotensin II, angiotensin I, and plasma renin activity are elevated, as reported with other ARBs and most likely secondary to blockade of the AT1 receptor.

\section{Dosage and tolerability}

Dose ranges from 20 to $80 \mathrm{mg}$ per day with an onset of action of 1-2 hours. Telmisartan has been shown to have a low discontinuation rate among patients. Side effects are less when compared to ACE inhibitors and it is an option when ACE inhibitors are not tolerated..$^{3,4}$

\section{Clinical properties}

Telmisartan is used in the management of hypertension as monotherapy or in combination with other types of

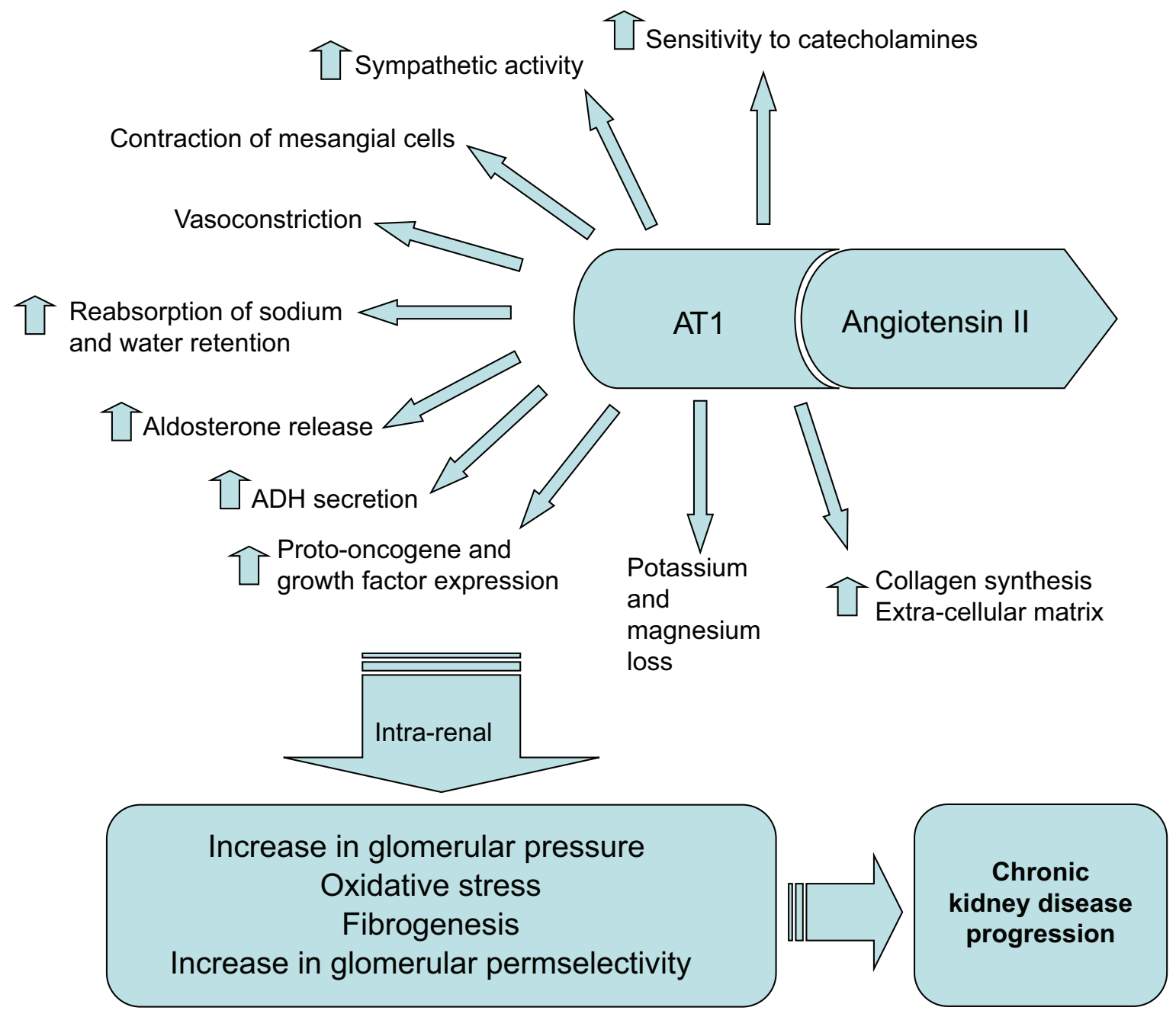

Figure I Effects of angiotensin II on the ATI receptor. 
antihypertensive medications. It is well known that ARBs are effective in reducing blood pressure as well as target organ damage, including left ventricular hypertrophy, stroke, proteinuria, and progression of CKD. Moreover, there are intrinsic properties that make this group of antihypertensives unique. It is known that in addition to ACE, the enzyme chymase influences the production of angiotensin II. ${ }^{5}$ Chymase is produced and stored in mast cells, endothelial cells, and mesenchymal cells. It is found in the heart, blood vessels, and the kidney. 5,6 ACE inhibitors do not inhibit chymase, thus angiotensin II can still be produced. ARBs block ACE and chymase-derived angiotensin II from activating the AT1 receptor. $^{5}$

\section{Metabolic effects}

There is evidence that in nondiabetic patients with CKD, a syndrome of insulin resistance is present even at the early stages of renal dysfunction. ${ }^{7}$ This renal insulin resistance syndrome may contribute to the increased incidence of cardiovascular events in CKD patients.

The peroxisome proliferator activated receptor (PPAR) plays an important role in the metabolism of lipids and carbohydrates and has been implicated in insulin resistance, metabolic syndrome, and atherosclerosis. Of the available ARBs, telmisartan has the greatest stimulating effect on PPAR- $\gamma$ and this effect decreases insulin resistance, increases insulin sensitivity, and reduces dyslipidemia, thereby providing greater target-organ protection. ${ }^{8,9}$ A recent study demonstrated that telmisartan not only increased insulin sensitivity but also decreased blood levels of triglyceride and free fatty acids; this action on lipid metabolism has been attributed to modulation of hepatic PPAR- $\gamma$ activity. ${ }^{10}$

\section{Vascular effects}

ARBs inhibit the growth of vascular smooth muscle cells and there is evidence that telmisartan does this to a greater extent. ${ }^{11,12}$ This effect is related to the blockade of the AT1 receptor and the activation of PPAR- $\gamma$, but there are other mechanisms that participate. ${ }^{11,12}$ Protein kinase B (AKT) is a proto-oncogene involved in signaling pathways that control cellular growth and differentiation. It has been reported that telmisartan inhibits vascular smooth muscle cell proliferation by inhibiting AKT activation. ${ }^{12}$

\section{Renal effects}

Although blood pressure reduction directly contributes to renoprotection, including reduction in proteinuria and slowing of CKD progression, ARBs and ACE inhibitors exert additional blood pressure-independent renoprotective effects via inhibition of the renin-angiotensin-aldosterone system (RAAS). ${ }^{1,13}$ It has been shown that RAAS blockade prevents fibrosis. Aldosterone per se stimulates fibrosis by stimulating the production of plasminogen activator inhibitor (PAI-1) and transforming growth factor- $\beta$ (TGF- $\beta$ ) and promoting inflammation and fibroblast growth and proliferation. ${ }^{14-19}$ PAI is an inhibitor of fibrinolysis and a regulator of extracellular matrix turnover. ${ }^{14}$ There are two types of PAI; PAI-2 is present in the placenta and PAI-1 is produced in the endothelium. On the other hand, TGF- $\beta$ induces the production of extracellular matrix, stimulates fibroblast proliferation, and inhibits collagenase production, resulting in accumulation of extracellular matrix proteins, collagen, and fibrosis. ${ }^{17,18}$

Angiotensin II also plays an important role in the development of fibrosis. ${ }^{1,20}$ Guo et al showed in a mice model that the ARB losartan and the ACE inhibitor enalapril decreased the levels of PAI-1 and reduced glomerular matrix deposition and glomerular mesangial cell activation. ${ }^{20}$ These effects are also evident with telmisartan. Yao et al and Tsunenari et al showed that telmisartan inhibited TGF- $\beta$ and that this inhibition was related to the activation of PPAR- $\gamma .^{21,22}$ Another study has recently demonstrated that telmisartan inhibits the activation of the pro-inflammatory nuclear transcription factor NF- $\kappa \mathrm{B}$ independently of PPAR $-\gamma^{23}$

In an experimental study that was not related to blood pressure control or proteinuria, it was demonstrated that telmisartan protected the kidneys of rats from iodine contrastinduced tubular damage. Because angiotensin II was elevated after tubular damage, the beneficial effect was attributed to angiotensin II blockade. ${ }^{24}$

In summary, the beneficial effects on vascular growth and fibrosis in the kidney via blockade of the AT1 receptor as well as the stimulation of PPAR- $\gamma$ make telmisartan useful in the prevention of hypertensive renal disease.

\section{Combination with other RAAS inhibitors}

Accumulating evidence from several recent clinical trials indicates that the combination of an ARB and an ACE inhibitor could produce more harm than benefit. The ONTARGET Study showed that telmisartan combined with ramipril decreased proteinuria but was associated with a decrease in the glomerular filtration rate. ${ }^{25,26}$ Other adverse effects were more common with the combination, such as hypotension and hyperkalemia. ${ }^{25,26}$ Acute renal failure is also more common with dual therapy. ${ }^{26}$ However, some have noted that combination therapy (dual ACE and AT1 receptor inhibition) 
is important in proteinuric glomerulopathies..$^{27,28,29}$ In general, it is recommended to closely monitor patients that are started on combination therapy.

It was recently reported that the combination of an ACE inhibitor with telmisartan in patients with type 2 diabetes was beneficial in reducing the amount of albuminuria and associated with less side effects like hyperkalemia and hypotension. ${ }^{30}$ The dose of telmisartan used in this study was $40 \mathrm{mg}$ daily compared with $80 \mathrm{mg}$ daily in the ONTARGET study, which may have contributed to the decreased development of side effects.

Combination treatment with the direct renin inhibitor aliskiren seems promising, but there are few studies currently available and it is recommended to be cautious until outcome studies become available. ${ }^{31}$

Use of telmisartan with the calcium channel blocker amlodipine has been shown to provide a notable improvement in blood pressure control in patients with stage 1 or 2 hypertension. ${ }^{32}$ In addition, combination therapy was associated with a reduced rate of peripheral edema compared with amlodipine monotherapy. Patients were reported to have tolerated well the combination therapy. Regarding combination therapy with diuretics, Neldam et al prospectively studied telmisartan in combination with hydrochlorothiazide versus amlodipine plus hydrochlorothiazide in older patients $(>$ or $=$ 60 years of age) with predominantly systolic hypertension. ${ }^{33}$ The study showed that telmisartan plus hydrochlorothiazide provided higher systolic blood pressure control rates and lower adverse events and discontinuation of therapy, particularly due to significantly less peripheral edema.

Telmisartan, like other ARBs, has been shown to be beneficial in diabetic nephropathy. Several studies have demonstrated a slowing in the progression of diabetic kidney disease and a decrease in the amount of proteinuria. ${ }^{34-36}$
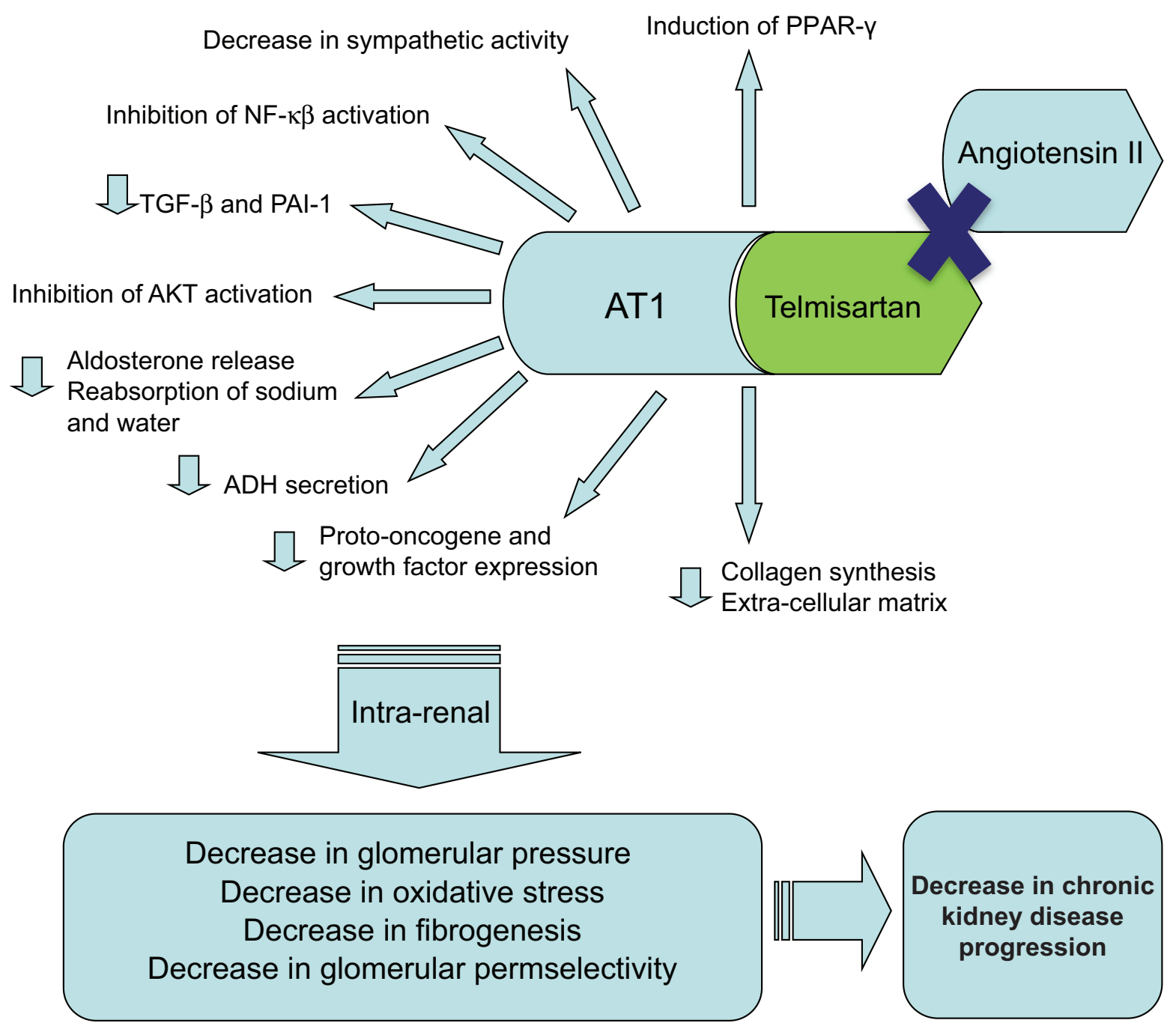

Figure 2 Effects of telmisartan via blockade of the ATI receptor. 
It has been reported that telmisartan is more effective in lowering proteinuria in hypertensive patients with overt diabetic nephropathy. ${ }^{35}$ This effect may be due, at least in part, to the inhibitory effects on ambulatory blood pressure variability and sympathetic nerve activity. In addition, telmisartan has a longer duration of action on nighttime blood pressure reduction. ${ }^{35}$ Furthermore, recent studies have indicated that telmisartan may be better in reducing proteinuria when compared to losartan, another commonly used ARB. ${ }^{35,36}$

\section{Conclusions}

The importance of blood pressure control as a means to prevent development or reduce progression of cardiovascular and kidney diseases has been firmly established. Like other blockers of the AT1 receptor, telmisartan is effective in reducing blood pressure when used alone or in combination with other antihypertensives. ${ }^{13}$ Its longer half-life, lipophilicity, and ability to stimulate PPAR- $\gamma$ seem to provide additional cardiovascular and renal protective properties that make it an attractive agent for global cardiovascular risk reduction (Figure 2).

\section{Disclosures}

The authors report no conflicts of interest.

\section{References}

1. Berl T. Review: renal protection by inhibition of the reninangiotensin-aldosterone system. J Renin Angiotensin Aldosterone Syst. 2009;10(1):1-8.

2. Lacourcière Y, Krzesinski JM, White WB, Davidai G, Schumacher H. Sustained antihypertensive activity of telmisartan compared with valsartan. Blood Press Monit. 2004;9:203-210.

3. Elliott HL. Focus on the ONTARGET results. J Hypertens. 2009; 27 Suppl 2:S8-S10.

4. de la Sierra A. Main results and clinical interpretations from the TRANSCEND study. J Hypertens. 2009;27 Suppl 2:S22-S25.

5. Huang XR, Chen WY, Truong LD, Lan HY. Chymase is upregulated in diabetic nephropathy: implications for an alternative pathway of angiotensin II-mediated diabetic renal and vascular disease. J Am Soc Nephrol. 2003;14(7):1738-1747.

6. Urata H, Boehm KD, Philip A. Cellular-localization and regional distribution of an angiotensin-II-forming chymase in the heart. J Clin Invest. 1993;91:1269-1281.

7. Becker B, Kronenberg F, Kielstein JT, et al. Renal insulin resistance syndrome, adiponectin and cardiovascular events in patients with kidney disease: the mild and moderated kidney disease study. $J \mathrm{Am}$ Soc Nephrol. 2005;16(4):1091-1098.

8. Benson SC, Pershadsingh HA, Ho CI, et al. Identification of telmisartan as a unique angiotensin II receptor antagonist with selective PPARgamma-modulating activity. Hypertension. 2004;43(5): 993-1002.

9. Miura Y, Yamamoto N, Tsunekawa S, et al. Replacement of valsartan and candesartan by telmisartan in hypertensive patients with type 2 diabetes. Diabetes Care. 2005;28:757-758.
10. Rong X, Li Y, Ebihara K, et al. An adipose tissue-independent insulinsensitizing action of telmisartan: a study in lipodystrophic mice. J Pharmacol Exp Ther. 2009;331(3):1096-1103.

11. Benson SC, Iguchi R, Ho CI, Yamamoto K, Kurtz TW. Inhibition of cardiovascular cell proliferation by angiotensin receptor blockers: are all molecules the same? J Hypertens. 2008;26(5):973-980.

12. Yamamoto K, Ohishi M, Ho C, Kurtz TW, Rakugi H. Telmisartaninduced inhibition of vascular cell proliferation beyond angiotensin receptor blockade and peroxisome proliferator-activated receptor\{gamma\} activation. Hypertension. 2009 Oct 12. [Epub ahead of print].

13. Blake R, Raij L, Hernandez Schulman I. Renal protection: are all antihypertensive drugs comparable? Curr Hypertens Rep. 2007;9(5): 373-379.

14. Yuan J, Jia R, Bao Y. Aldosterone upregulates population of plasminogen activator inhibitor-1 by renal mesangial cells. J Biochem Mol Biol. 2007;40:180-188.

15. Juknevicius I, Segal Y, Kren S, Lee R, Hostetter TH. Effect of aldosterone on renal transforming growth factor-beta. Am J Physiol Renal Physiol. 2004;286:F1059-F1062.

16. Cortinovis M, Perico N, Cattaneo D, Remuzzi G. Aldosterone and progression of kidney disease. Ther Adv Cardiovasc Dis. 2009;3(2): 133-143.

17. Wolf $\mathrm{G}$. Renal injury due to renin-angiotensin-aldosterone system activation of the transforming growth factor- $\beta$ pathway. Kidney Int. 2006;70:1914-1919.

18. Sharma K, Ziyadeh FN. The emerging role of transforming growth factor- $\beta$ in kidney disease. Am J Physiol. 1994;266:F829-F842.

19. Remuzzi G, Cattaneo D, Perico N. The aggravating mechanisms of aldosterone on kidney fibrosis. J Am Soc Nephrol. 2008;19(8):1459-1462.

20. Guo S, Kowalewska J, Wietecha TA, et al. Renin-angiotensin system blockade is renoprotective in immune complex-mediated glomerulonephritis. J Am Soc Nephrol. 2008;19(6):1168-1176.

21. Yao Y, Zou R, Liu X, et al. Telmisartan but not valsartan inhibits TGF-beta-mediated accumulation of extracellular matrix via activation of PPARgamma. J Huazhong Univ Sci Technolog Med Sci. 2008;28(5):543-548.

22. Tsunenari I, Ohmura T, Seidler R, et al. Renoprotective effects of telmisartan in the 5/6 nephrectomised rats. J Renin Angiotensin Aldosterone Syst. 2007;8(2):93-100.

23. Nakano A, Hattori Y, Aoki C, Jojima T, Kasai K. Telmisartan inhibits cytokine-induced nuclear factor-kappaB activation independently of the peroxisome proliferator-activated receptor-gamma. Hypertens Res. 2009;32(9):765-769.

24. Duan SB, Wang YH, Liu FY, et al. The protective role of telmisartan against nephrotoxicity induced by $\mathrm{X}$-ray contrast media in rat model. Acta Radiol. 2009;50(7):754-759.

25. Basile J. Lessons learned from the ONTARGET and TRANSCEND trials. Curr Atheroscler Rep. 2009;11(5):371-376.

26. ONTARGET Investigators, Yusuf S, Teo KK, Pogue J, et al. Telmisartan, ramipril, or both in patients at high risk for vascular events. 2008;358(15):1547-1559.

27. Onuigbo MA. Analytical review of the evidence for renoprotection by renin-angiotensin-aldosterone system blockade in chronic kidney disease - a call for caution. Nephron Clin Pract. 2009;113(2): c63-c69.

28. Ruggenenti P, Remuzzi G. Proteinuria: is the ONTARGET renal substudy actually off target? Nat Rev Nephrol. 2009;5(8):436-437.

29. Mann JF, Tobe S, Teo KK, Yusuf S. Is therapy of people with chronic kidney disease ONTARGET? Nephrol Dial Transplant. 2009 Oct 23. [Epub ahead of print].

30. Mazerska M, Myśliwiec M. Telmisartan lowers albuminuria in type 2 diabetic patients treated with angiotensin enzyme inhibitors. Adv Med Sci. 2009;54(1):37-40.

31. Doulton TW, Macgregor GA. Combination renin-angiotensin system blockade with the renin inhibitor aliskiren in hypertension. J Renin Angiotensin Aldosterone Syst. 2009 Jul 17. [Epub ahead of print]. 
32. Littlejohn TW 3rd, Majul CR, Olvera R, et al. Study Investigators. Results of treatment with telmisartan-amlodipine in hypertensive patients. J Clin Hypertens (Greenwich). 2009;11(4):207-213.

33. Neldam S, Edwards C; ATHOS Study Group. Telmisartan plus HCTZ vs amlodipine plus HCTZ in older patients with systolic hypertension: results from a large ambulatory blood pressure monitoring study. Am J Geriatr Cardiol. 2006;15(3):151-160.

34. Kalaitzidis R, Bakris GL. Effects of angiotensin II receptor blockers on diabetic nephropathy. J Hypertens. 2009;27 Suppl 5:S15-S21.
35. Masuda S, Tamura K, Wakui H, et al. Effects of angiotensin II type 1 receptor blocker on ambulatory blood pressure variability in hypertensive patients with overt diabetic nephropathy. Hypertens Res. 2009;32(11):950-955.

36. Bakris G, Burgess E, Weir M, Davidai G, Koval S. AMADEO Study Investigators. Telmisartan is more effective than losartan in reducing proteinuria in patients with diabetic nephropathy. Kidney Int. 2008;74(3):364-369.

\section{Publish your work in this journal}

The International Journal of Nephrology and Renovascular Disease is an international, peer-reviewed open-access journal focusing on the pathophysiology of the kidney and vascular supply. Epidemiology, screening, diagnosis, and treatment interventions are covered as well as basic science, biochemical and immunological studies. The journal welcomes original research, clinical studies, reviews \& evaluations, expert opinion and commentary, case reports and extended reports. The manuscript management system is completely online and includes a very quick and fair peerreview system, which is all easy to use. Visit http://www.dovepress.com/ testimonials.php to read real quotes from published authors.

Submit your manuscript here: http://www.dovepress.com/international-journal-of-nephrology-and-renovascular-disease-journal 